Rev. Elet. em Gestão, Educação e Tecnologia Ambiental (e-ISSN: 2236-1170)

\title{
CONHECENDO AS FORMAS DE DESCARTES DO ÓLEO SATURADO DE COZINHA PARA VERIFICAR A EDUCAÇÃO AMBIENTAL NA ESCOLA
}

\author{
Fabio Barcelos Barcelos Segatto ${ }^{1}$ \\ 1'segatto.fabio@gmail.com
}

http://dx.doi.org/10.5902/223611707602

\section{RESUMO}

Dentre vários produtos considerados vilões para a natureza, está um resíduo de alto uso caseiro e comercial, que é o óleo usado de cozinha também conhecido como óleo saturado, que ao ser descartado de forma inadequado ao meio ambiente, ele pode provocar sérios danos à natureza, sendo assim, este trabalho faz uma breve análise de dados coletados comparados com estudos literários sobre a real necessidade da Educação Ambiental na vida das pessoas, a fim de levar uma conscientização ambiental à população, possibilitando um conhecimento prévio dos riscos causados à natureza e à humanidade, com ações inadequadas ao meio ambiente.

\begin{abstract}
Among several products considered villains to nature, is a residue of high home and commercial use, which is used cooking oil also known as saturated oil, which when discarded so inappropriate to the environment, it can cause serious damage to nature, so this paper makes a brief analysis of data collected compared to literary studies about the real need for environmental Education in people's lives, to bring environmental awareness to the public, allowing a prior knowledge of the risks caused to nature and humanity, with inappropriate actions on the environment.
\end{abstract}

\section{INTRODUÇÃO}

Um dos grandes problemas do mundo e para a sociedade, é saber o que vai fazer com a grande quantidade de lixo que se é produzido no meio social como, por exemplo, o óleo de origem vegetal ou animal que sempre foi utilizado pelo ser humano com vários objetivos, entre um deles o de ser usado na fritura de alimentos, contudo após algum tempo utilizado, ele passa a não ser bom para o uso de frituras, por passar a ter aromas e cheiros dos alimentos que foram fritos anteriormente, sendo assim tendo que ser descartado. Assim, muitos o jogam direto na pia ou no quintal e ao cair no solo ou nas redes de esgoto, eles acarretam a poluição do solo, da água superficial, dos lençóis subterrâneos e das redes de drenagem, passando a deixar de ser uma solução individual e a passar a ser um problema social. 


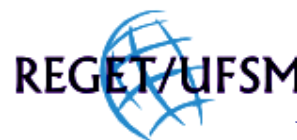

SEGATTO, v(10), nº 10, p. 2122-2129, JAN-ABR, 2013.

Rev. Elet. em Gestão, Educação e Tecnologia Ambiental (e-ISSN: 2236-1170)

Segundo Humberto (2007), pesquisas apontam que os brasileiros consomem aproximadamente 3 bilhões de litros de óleo de cozinha por ano. No Espírito Santo, esse consumo é de aproximadamente 150 milhões. Depois de usado, parte desse óleo é jogado na rede de drenagem pluvial e rede de esgoto. Isso acarreta aumento do custo no tratamento dessas redes em até $45 \%$ e também causa entupimento das tubulações.

E no Espírito Santo, a CESAN - Companhia Espírito Santense de Saneamento do Estado, através de um Projeto de Educação ambiental chamado de Projeto Gordura Zero promove uma sensibilização com os seus clientes, principalmente os comerciantes de bares e restaurantes à importância do descarte correto do óleo de cozinha usado.

Segundo Cascino (1999) as questões ambientais, atualmente, são alvos de debates e preocupações das comunidades, já que, há a consciência de que a fragilidade da natureza coloca em risco a sobrevivência humana.

Diante desse exposto, promoveu-se este estudo para avaliar o perfil de um grupo de familiares de alunos que participaram no ano de 2012 de um Projeto de Educação Ambiental da escola EMEF Placidino Passos, no município de Aracruz, no Espírito Santo, chamado de Educar com Responsabilidade Ambiental, com o objetivo de verificar o que estes familiares fazem com o óleo de cozinha usado em suas casas.

Já que a forma mais viável de se levar informações à população sobre questões ambientais e ajudando a diminuir os impactos gerados pelo homem é através de projetos educacionais, conforme afirma, (LOUREIRO, 2000) onde diz que, para a real transformação do quadro de crise estrutural e conjuntural em que vivemos a Educação Ambiental, por definição, é elemento estratégico na formação da ampla consciência crítica das relações sociais e de produção que situam a inserção humana na natureza.

\section{METODOLOGIA}

Com a intenção em pesquisar se houve uma conscientização dos alunos do Projeto Educar com Responsabilidade Ambiental da Escola EMEF Placidino Passos em Aracruz com os seus familiares, foi feito um levantamento através de um questionário (em anexo), com um grupo de 83 pessoas responsáveis pelos alunos do projeto.

Este trabalho foi dividido em etapas, das quais primeiro foi feito um trabalho de conscientização com os alunos sobre a importância do descarte ou reaproveitamento ideal do óleo de cozinha usado para que não seja jogado de forma inadequada a poluir o meio ambiente. Depois dessa etapa, foi feito um trabalho de pesquisa com os familiares dos alunos do projeto, para saber o que eles faziam com o óleo de cozinha saturado, e por último, foi feito o questionário, do qual Marconi \& Lakatos (2002) diz que o questionário é um instrumento de coleta de dados construído por uma série ordenada de perguntas, que devem ser respondidas por escrito sem a presença do entrevistador. 


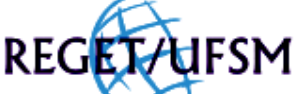

SEGATTO, v(10), nº 10, p. 2122-2129, JAN-ABR, 2013.

Rev. Elet. em Gestão, Educação e Tecnologia Ambiental (e-ISSN: 2236-1170)

\section{RESULTADOS E DISCUSSÕES}

Diante dos questionários respondidos, houve a possibilidade de quantificar, tabular e transformar em gráficos para melhor visualização dos resultados obtidos com o trabalho feito dentro do Projeto.

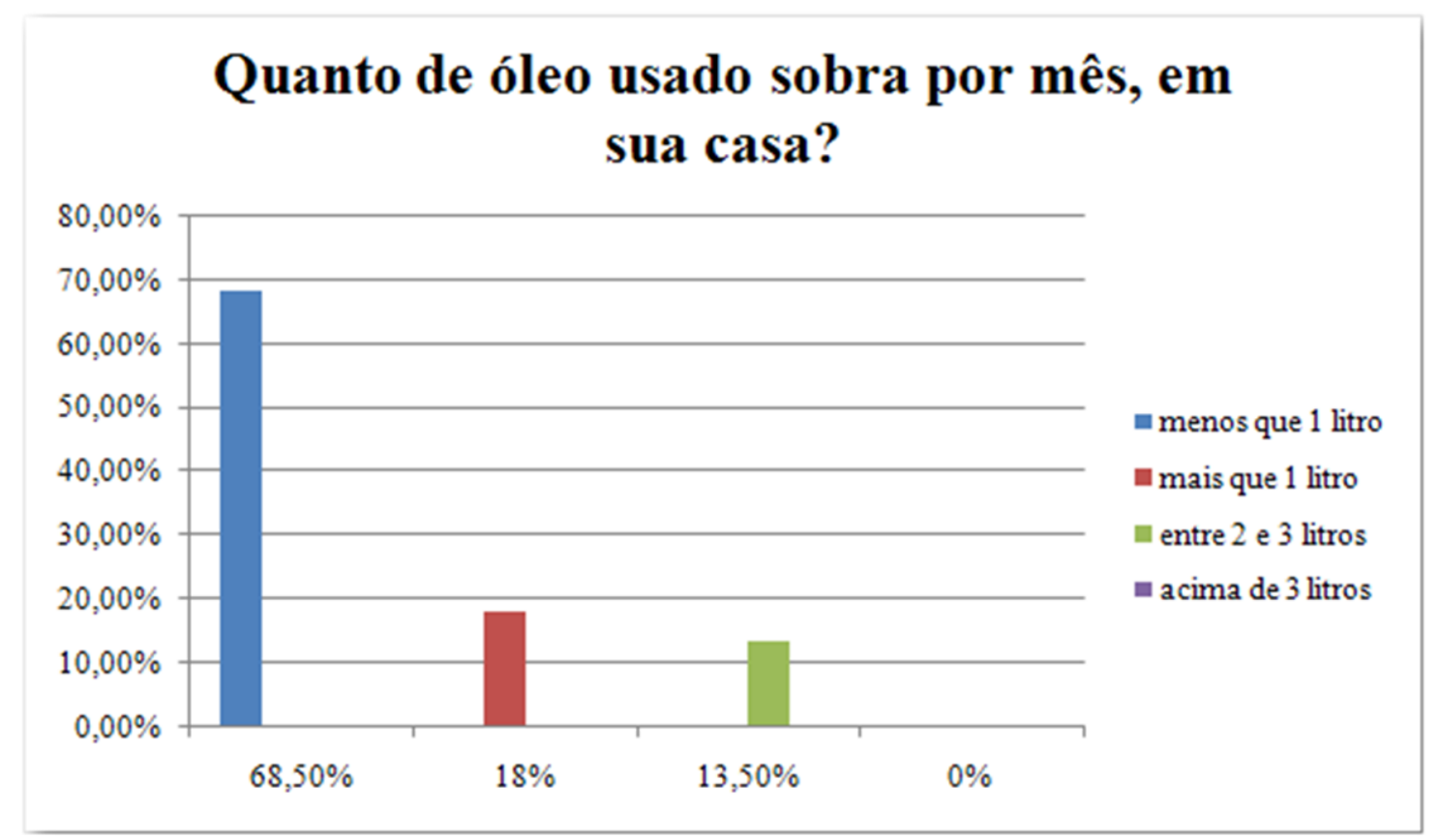

Gráfico 1 - Porcentagem de pessoas que responderam a quantidade de óleo que sobra no mês em suas casas. 
SEGATTO, v(10), nº 10, p. 2122-2129, JAN-ABR, 2013.

Rev. Elet. em Gestão, Educação e Tecnologia Ambiental (e-ISSN: 2236-1170)

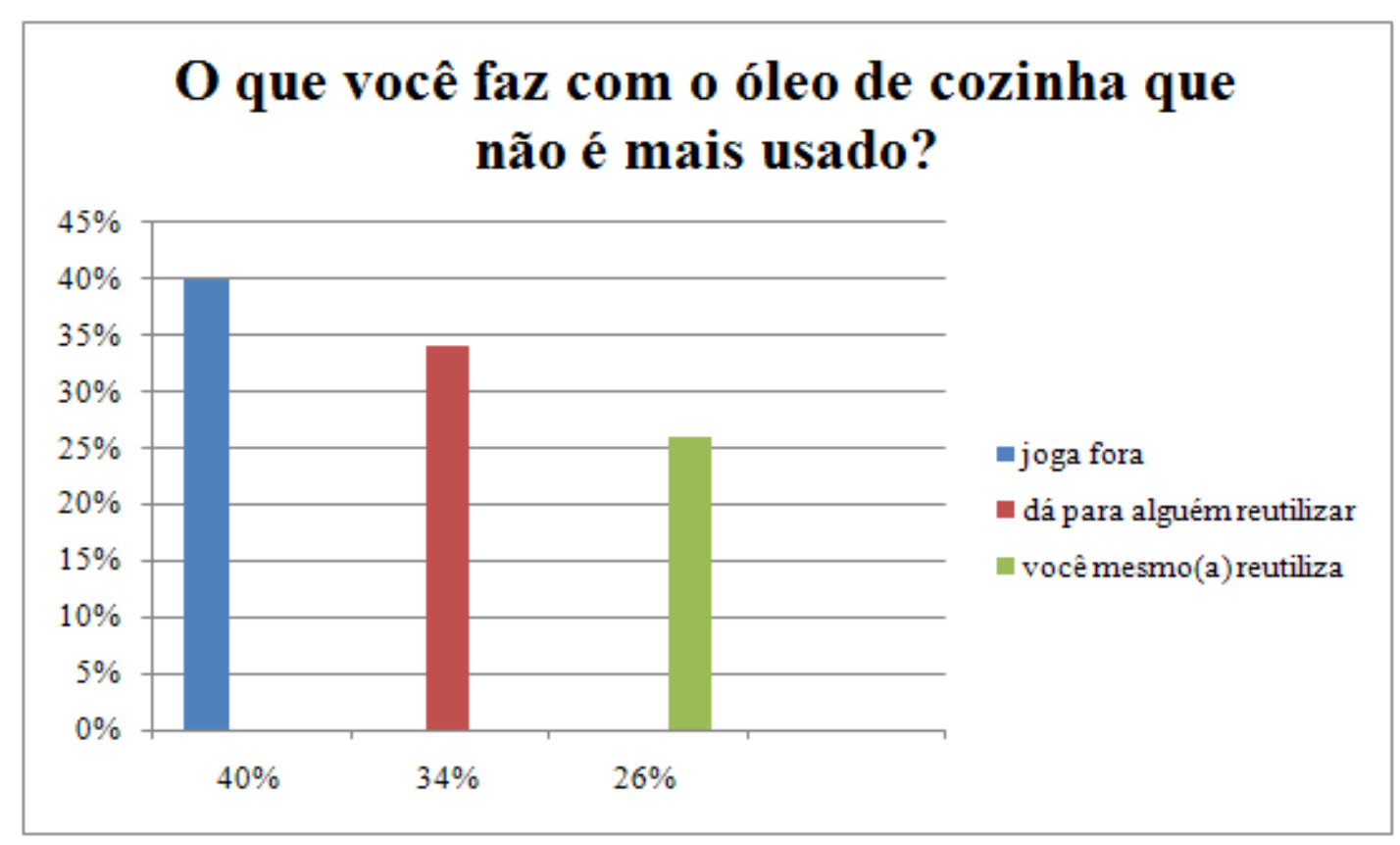

Gráfico 2 - Porcentagem de pessoas que responderam o que fazem com o que sobra de óleo usado mês em suas casas. 
SEGATTO, v(10), nº 10, p. 2122-2129, JAN-ABR, 2013.

Rev. Elet. em Gestão, Educação e Tecnologia Ambiental (e-ISSN: 2236-1170)

\section{Se você joga o óleo usado fora, você joga} onde?

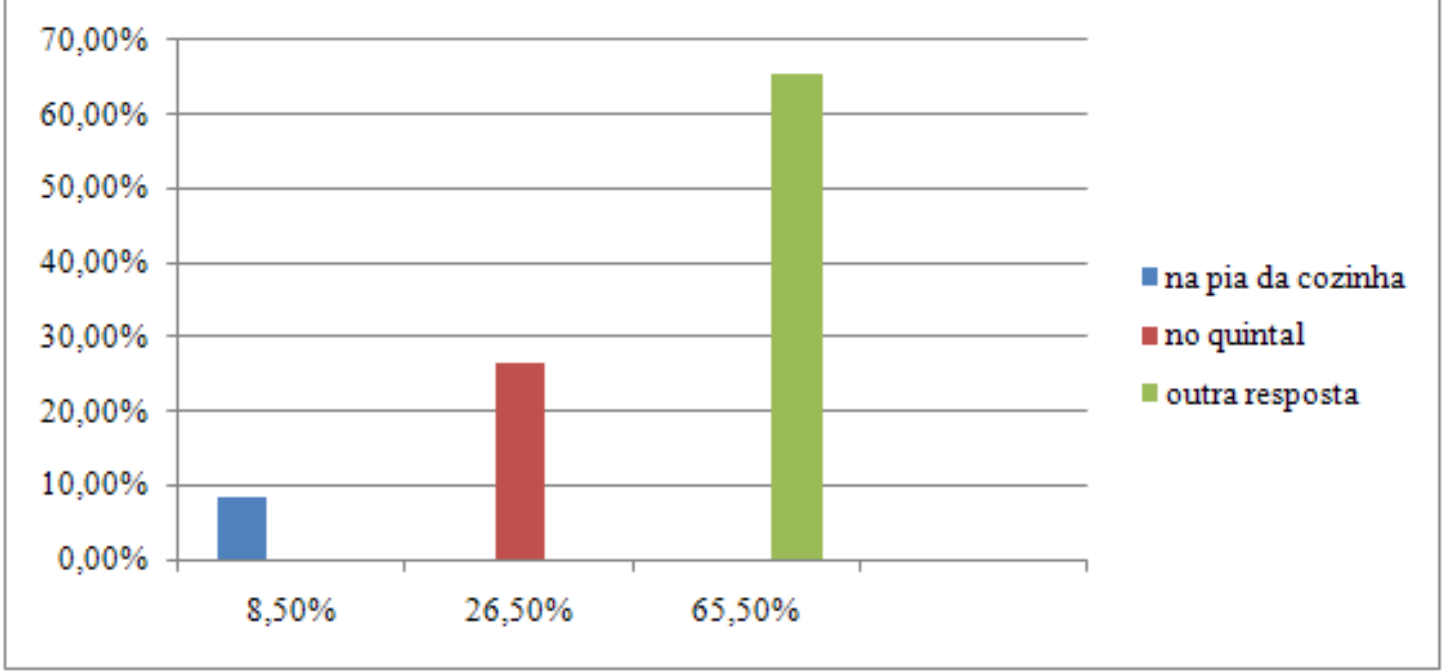

Gráfico 3 - Porcentagem de pessoas que responderam onde jogam fora do que sobra de óleo usado em suas casas. 


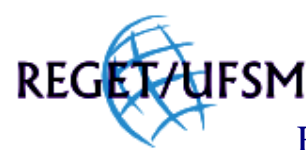

SEGATTO, v(10), nº 10, p. 2122-2129, JAN-ABR, 2013.

Rev. Elet. em Gestão, Educação e Tecnologia Ambiental (e-ISSN: 2236-1170)

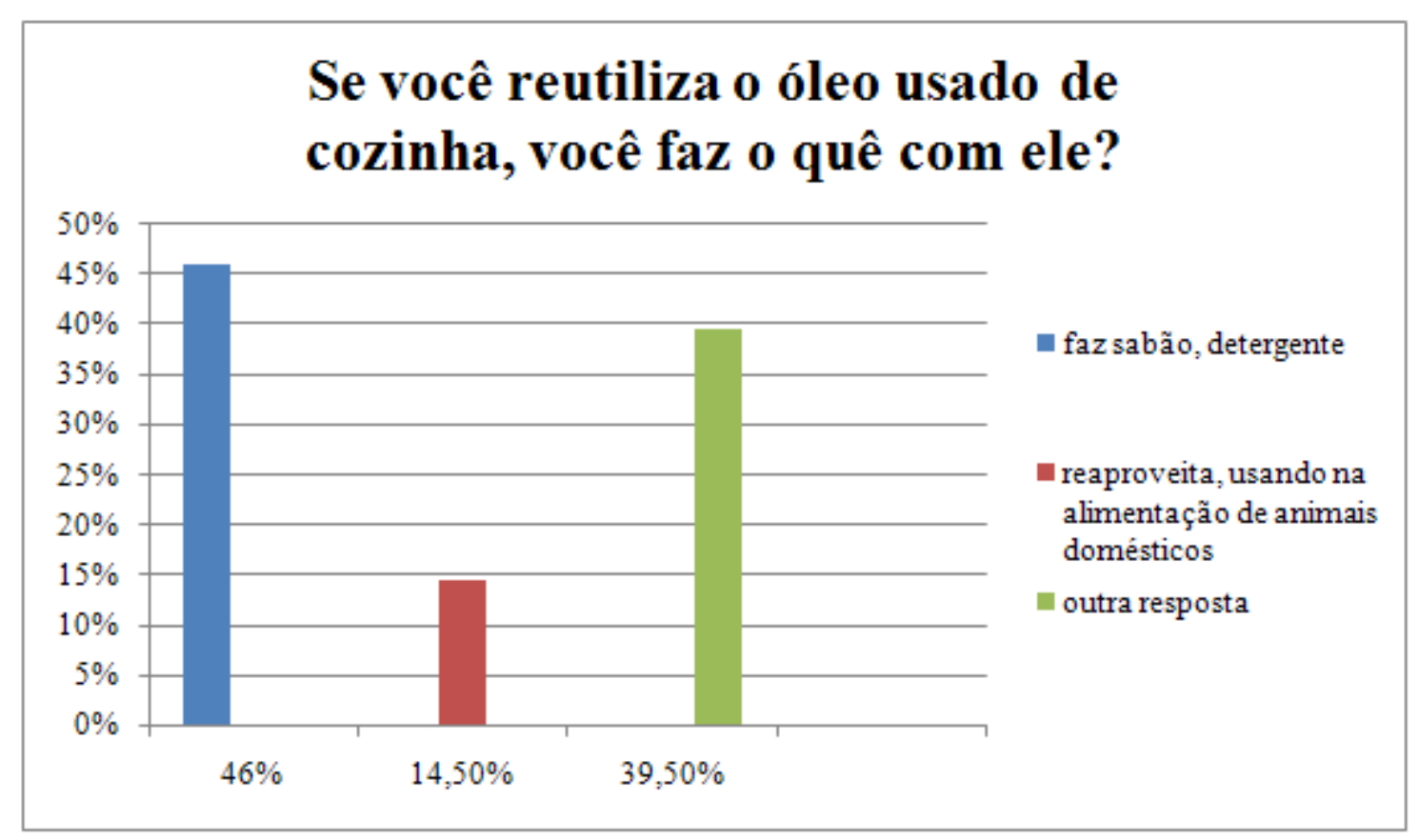

Gráfico 4 - Porcentagem de pessoas que responderam como reutilizam a sobra de óleo usado em suas casas.

A partir dos gráficos percebeu-se a importância do trabalho de Educação ambiental na escola com os alunos e principalmente com os familiares destes alunos, pois ao comparar o gráfico 1 com o gráfico 2, percebeu-se que por mínimo que seja o óleo descartado no ambiente, ele tem que ser descartado corretamente, pois segundo a (SABESP, 2008), Cada litro de óleo despejado no esgoto tem capacidade para poluir cerca de um milhão de litros de água, encarecendo o tratamento das redes de esgoto.

Ao analisar o gráfico 3, constatou-se que $35 \%$ dos entrevistados responderam que descartam inadequadamente o óleo usado no ambiente ou desconhecem essas formas de descarte, jogando na pia ou no quintal, fazendo com que contribuem para a poluição ambiental e como (PONTES \&ALBERCINI, 2004) afirmam que dessa forma, as pessoas comprometem a vida da base da cadeia alimentar aquática, que são os fitoplânctons, ao causar este tipo de impacto ambiental aquático.

E 65\% que responderam este questionário, responderam Outra Resposta ${ }_{2}$ onde há a compreensão dessa questão no gráfico 4, em que ao analisar este último gráfico, notou-se que $60,5 \%$ dos entrevistados reutilizam o óleo que sobra sem prejudicar o meio ambiente, usando este óleo saturado de cozinha na fabricação de sabão ou usado na alimentação de animais domésticos, lembrando que dos 39,5\% que responderam Outra Resposta, alguns disseram que armazenam o óleo usado em recipientes de plástico para serem despejados para a coleta de lixo, do qual segundo o site da Prefeitura de Aracruz, existe um Projeto chamado Óleo Bom, o qual retira o óleo saturado dos locais geradores, transformando-os em sabão, além de gerar renda para as pessoas coletoras desse tipo de resíduo. 


\section{CONCLUSÕES}

Desse modo, certificou-se que a Educação Ambiental tem um papel importante na conscientização de boa parte dos familiares e alunos como se esperava nesta pesquisa, como Boff (2004) menciona que, a Educação Ambiental vem se tornando essencial para a população na medida em que ela reivindica e prepara os cidadãos para exigir justiça social, cidadania nacional e planetária, autogestão e ética nas relações sociais e com a natureza.

\section{REFERÊNCIAS BIBLIOGRÁFICAS}

ALBERECI, Rosana Maria; PONTES, Flávia Fernandes Ferraz de.

Reciclagem de óleo comestível usado através da fabricação de sabão. Espírito Santo do Pinhal: Engenharia Ambiental Centro Regional Universitário de Espírito Santo do Pinhal v.1, n.1, p.073-076, jan./dez., 2004.

BOFF, Leonardo. Saber cuidar: ética do humano - compaixão pela terra. 11ạ ed. Petrópolis - RJ:Vozes, 2004.

CASCINO, F. Educação Ambiental: Princípios, História e Formação de Professores. São Paulo: Senac, 1999.

COMPANHIA DE SANEAMENTO BÁSICO DO ESTADO DE SÃO PAULO. SABESP. 2008. Programa de uso racional da água. Disponível em: <http://www.sabesp.com.br>. Acessado em 02/01/2013.

HUMBERTO 2007. Projeto transforma resíduos em oportunidades de negócios. Portal fator Brasil. Disponível em: <http://www.revistafator.com.br/ver_noticia. php?no t=11650>. Acesso em: 01 de Janeiro de 2013.

Lei de Diretrizes e Bases da Educação. Disponível em: <http://portal.mec.gov.br/seed/arquivos/pdf/tvescola/leis/lein9394.pdf>. Acesso em: 01 de Janeiro de 2013.

LOUREIRO, C.F.B.; LAYRARGUES, P.P. Educação ambiental nos anos noventa. Mudou, mas nem tanto. Políticas Ambientais, ano 9, n25, dez. 2000.

Parâmetros Curriculares Nacionais - PCN's (Meio Ambiente/Saúde), de 1997. Disponível em: <http://portal.mec.gov.br/seb/arquivos/pdf/livro091.pdf>. Acesso em: 01 de Janeiro de 2013.

MARCONI, M.A; LAKATOS, E.M. Técnicas de pesquisas. 5. ed. São Paulo:Atlas 2002.

Projeto Gordura Zero. Disponível em:<http://www.cesan.com.br/page. php?26>. Acesso em: 01 de Janeiro de 2013.

Projeto Óleo Bom. Disponível em:<http://www.pma.es.gov.br/noticia/832/>. Acessado em 02/01/2013.

Secretaria de Educação Fundamental. Parâmetros curriculares nacionais: terceiro e quarto ciclos: apresentação dos temas transversais / Secretaria de Educação Fundamental. - Brasília: MEC/SEF, 2001436 p.

\section{Anexo}

Questionário utilizado para a compreensão do trabalho:

1. Quanto de óleo usado em frituras, sobra por mês em sua cozinha? 


\section{REGEJAUFSM}

SEGATTO, v(10), nº 10, p. 2122-2129, JAN-ABR, 2013.

Rev. Elet. em Gestão, Educação e Tecnologia Ambiental (e-ISSN: 2236-1170)

( ) menos de 1 litro ( ) mais de 1 litro ( ) entre 2 e 3 litros

( ) acima de 3 litros

2. O que você faz com o óleo de cozinha que não presta mais para frituras?

( ) joga fora ( ) dá para alguém, reutilizar ( ) você mesma(o) reutiliza

3. Se você joga o óleo usado fora, você joga onde?

( ) na pia da cozinha ( ) no quintal ( ) outra resposta.

Qual?

4. Se você reutiliza o óleo usado de cozinha, reutiliza fazendo o quê?

( ) fazer sabão, detergente ( ) reaproveita na alimentação humana ou de animais domésticos ( ) outra resposta.

Qual? 